\title{
Off-label use of medicines in children: can available evidence avoid useless paediatric trials?
}

\author{
The case of proton pump inhibitors for the treatment of gastroesophageal reflux disease
}

\author{
Giovanni Tafuri • Francesco Trotta • \\ Hubert G. M. Leufkens • Nello Martini • \\ Luciano Sagliocca $\cdot$ Giuseppe Traversa
}

Received: 14 March 2008 / Accepted: 25 August 2008 / Published online: 17 September 2008

(C) The Author(s) 2008. This article is published with open access at Springerlink.com

\begin{abstract}
Purpose In some cases of drug therapy, the available evidence might be sufficient to extend the indications to children without further clinical studies.

Methods We reviewed the available evidence for one of the categories of drugs most frequently used off-label in children: proton pump inhibitors (PPIs) used for the treatment of gastroesophageal reflux disease (GERD). A classification of the appropriateness of off-label use of PPIs in children with GERD was also performed.

Results Of the five PPIs evaluated, only omeprazole has a paediatric indication in Europe. Overall, 19 clinical trials were retrieved and evaluated on the basis of pharmacokinetics, efficacy and safety data. The off-label use of omeprazole, esomeprazole and lansoprazole in children was evaluated as appropriate given the consistent available evidence retrieved in literature.
\end{abstract}

G. Tafuri · H. G. M. Leufkens

Utrecht Institute for Pharmaceutical Sciences, Utrecht University, P.O. Box 80 082, 3508 TB Utrecht, The Netherlands

G. Tafuri $\cdot$ F. Trotta $(\bowtie) \cdot$ N. Martini $\cdot$ G. Traversa

Italian Medicines Agency (AIFA),

via della Sierra Nevada 60,

00144 Rome, Italy

e-mail: f.trotta@aifa.gov.it

H. G. M. Leufkens

Medicines Evaluation Board (MEB),

P.O. Box 16229, 2500 BE The Hague, The Netherlands

L. Sagliocca

Local Health Unit Salerno 1,

via Giovanni Falcone 70,

84014 Nocera Inferiore, SA, Italy
Conclusion This study demonstrates the existence of a large body of clinical evidence on the use of PPIs in children. Regulatory agencies and ethical committees should cope with this issue for ethical reasons to avoid unnecessary trial replication.

Keywords Children · European Medicines Agency · Food and Drug Administration - Gastroesophageal reflux disease . Off-label · Proton pump inhibitors

\section{Introduction}

The use of unlicensed and off-label medicines in children is widespread and has raised an increasing concern over the last years. In the European Union (EU), 50\% or more of the medicines used in children have only been studied in adults, and not necessarily for the same indication [1]. The general lack of information and appropriate pharmaceutical formulations for use in children may expose them to unwanted adverse events or underdosing without the expected efficacy. The need for more studies to obtain paediatric information for medicines used in children is now a matter of consensus on a global basis $[2,3]$. The awareness of off-label drug usage in the daily practice by paediatricians and the need to identify specific off-label clinical priorities in paediatrics have been documented in an observational study conducted in 32 Italian Departments of Paediatrics [4].

The policy implemented in the USA, culminating in the Pediatric Research Equity Act of 2003, paved the way for the new European legislation (the 'Paediatric Regulation'), which was adopted in January 2007 with the objective to guide the development and authorisation of medicines for 
use in children aged $0-17$ years [5-7].This legislation was designed to better protect the health of children in the EU. A Paediatric Committee was established within the European Medicines Agency (EMEA) with the intent to provide scientific opinions on any development plan for paediatric medicines. The Committee has identified therapeutic areas where clinical studies on medicinal products for children are considered both a priority and a prerequisite for granting a paediatric indication [8].

A recent draft guidance has been issued by the U.S. Food and Drug Administration (FDA) with the aim to effectively manage the off-label phenomenon, enabling sponsors to distribute publications about off-label use of approved drugs to prescribers [9]. The potential pros and cons of this approach have been strongly debated among the scientific and regulatory community at the international level [10].

The current scenario on paediatric research and regulation raises a new challenging question: is it always necessary to perform additional clinical studies in children? Our hypothesis is that, in some instances, the evidence already available may be sufficient to extend the indications to children without further clinical studies. This would allow the translation of the existing evidence into clinical practice, minimising regulatory hurdles and avoiding the unethical replication of trials.

To test this hypothesis we reviewed the available evidence for one of the categories of drugs most frequently used off-label in children: proton pump inhibitors (PPIs) for the treatment of gastroesophageal reflux disease (GERD). The rationale for choosing PPIs stems from the following considerations. The role of PPIs for the treatment of GERD is identified as a paediatric need by the EMEA Paediatric Committee [8]. However, although PPIs do not have an indication for GERD in infants, clinical guidelines from the North American Society for Pediatric Gastroenterology and Nutrition address the use of PPIs for this age group [11]. Which line of action should be followed to better protect paediatric patients? This question is of particular importance given the enormous increase in the use of PPIs in infants for presumed GERD that has been documented (in the 6 years from 1999 through 2004, there was a more than sevenfold increase) and the largely inappropriate prescription of PPIs in children presenting physiological GERD that has been recently reported $[12,13]$.

The aim of the study was to review the clinical evidence available in the published scientific literature concerning the use of PPIs for the treatment of GERD in the paediatric population in order to establish whether the absence of authorised indications can be justified. An additional aim of the study is to describe possible differences in the PPIapproved indications for the treatment of GERD in the paediatric population in the two largest regulatory agencies, EMEA and FDA.

\section{Methods}

We performed a preliminary search to determine the regulatory status of approved PPIs (omeprazole, esomeprazole, lansoprazole, rabeprazole and pantoprazole) in Europe and the USA. The European summaries of product characteristics (SPCs) were retrieved from the EUDRANET database (http://ec.europa.eu/idabc/en/document/2291); the U.S. patient information leaflets were retrieved from the FDA website (www.fda.gov). The update of these documents was surveyed until June 2008. Information on paediatric indications was abstracted from such documents, and a comparison between Europe and the USA was then carried out.

A comprehensive search on the MEDLINE and EMBASE databases (January 1990-June 2008) was performed. All clinical trials on the off-label use of PPIs for the treatment of GERD in children (age 0-17 years) were considered eligible for inclusion. For the purpose of this analysis, the following parameters were assessed: study design, trial information (country, centres), objectives (endpoints), patients population, study duration, posology, formulation and main findings (as reported by the authors). Given the objective of the study, the analysis was restricted to the trials conducted on patients' age ranges not already included in approved EU indications (e.g. for omeprazole, only studies including children aged $0-2$ years were analysed).

We defined a priori a common data acquisition form to be completed using the information collected from the selected articles [14-32]. The information was used to assess the available evidence on the pharmacokinetics (PK), efficacy and safety of each drug. The safety profile of each drug was evaluated through a comparison of adverse events (AEs) for adults listed in SPC versus the AEs reported in paediatric trials. A specific search on the MEDLINE and EMBASE databases was performed in order to retrieve safety data collected through reviews and observational studies.

On the basis of the retrieved evidence, a classification of the appropriateness of off-label use of PPIs in children with GERD was performed. Each drug was ranked as having a high, moderate or scarce appropriateness when administered in children, depending on the fulfilment of three prespecified criteria. Specifically, a high appropriateness was attributed to a compound when at least two efficacy trials and two PK studies were retrieved and a comparable safety profile versus adults was assessed. Lack of compliance with one or more of the above-mentioned criteria leads to a decrease in the ranking of appropriateness. For the classification of appropriateness, strength of the endpoints and robustness of the study designs have been also considered as two additional criteria. The use of 24-h pH 
monitoring and/or endoscopy, although surrogate endpoints, are considered to be acceptable predictors of efficacy [33]. Double-blind randomised controlled trials were considered the highest level of evidence for testing medicines.

\section{Results}

The five PPIs currently marketed in the EU-omeprazole, esomeprazole, lansoprazole, rabeprazole and pantoprazolewere approved through a mutual recognition procedure. Of these five PPIs, only omeprazole has a paediatric indication (i.e. children aged $\geq 2$ years). Esomeprazole, which is the $S$-isomer of omeprazole, does not formally have any paediatric indication, although the approved European SPC contains information on posology in children under the age of 12 years. At the end of June 2007 further information on the posology in adolescents in terms of the treatment of GERD was added for the pantoprazole SPC. However, no changes were included in the therapeutic indication section of the SPC.

The scenario in the USA appears to be different: three out of five compounds (omeprazole, esomeprazole, lansoprazole) are currently authorised for children, although with the exclusion of infant and neonate age groups (Table 1). It is noteworthy that lansoprazole and esomeprazole are approved for children aged 1-17 in the USA but not in the EU. The most recently marketed PPIs (rabeprazole and pantoprazole) are not indicated for use in children in the USA nor in the EU.

Nineteen clinical trials testing PPIs in the treatment of GERD in children were retrieved; these are summarised in Table 2. Of these, eight were multicentre trials. More than $40 \%$ of the trials evaluated were conducted in the USA.

Table 1 Approved indications of PPIs for the treatment of GERD in the European Union and the USA

\begin{tabular}{lll}
\hline Drug & EU indication & US indication \\
\hline $\begin{array}{l}\text { Omeprazole } \\
\text { Esomeprazole }\end{array}$ & $\begin{array}{c}\text { GERD } \geq 2 \text { years } \\
\text { Not authorised in } \\
\text { children }\end{array}$ & GERD 2-16 years \\
Lansoprazole & $\begin{array}{c}\text { Not authorised in } \\
\text { children }\end{array}$ & GERD 1-17 years \\
Pantoprazole & $\begin{array}{c}\text { Not authorised in } \\
\text { children }\end{array}$ & Not authorised in \\
Rabeprazole & $\begin{array}{c}\text { Not authorised in } \\
\text { children }\end{array}$ & $\begin{array}{c}\text { Not authorised in } \\
\text { children }\end{array}$ \\
\hline
\end{tabular}

PPI, Proton pump inhibitors; GERD, gastroesophageal reflux disease ${ }^{\text {a }}$ Information on posology in adolescents ( $\geq 12$ years) with GERD is available in the summaries of product characteristics (SPC)
Findings on omeprazole consisted of six efficacy trials, two also focussing on the PK profile. The study duration ranged from 7 days to 3 months, and a total of 151 children were enrolled; three studies were randomised controlled trials (RCTs).

The evidence for lansoprazole consisted of six studies (one was a RCT), testing efficacy and PK, with a study duration ranging from 5 days to 3 months. Overall, 282 patients were enrolled. Four RCTs on esomeprazole were retrieved: these were aimed at defining the PK, efficacy and safety profile, with a total of 257 enrolled children. The improvement of GERD symptoms was investigated in two efficacy trials (one was a RCT) with pantoprazole. The population enrolled consisted of 68 children with a mean study duration of 1.5 month. Finally, for the latest marketed PPI, rabeprazole, only one trial investigating PK and safety was retrieved, with a population involving 24 children.

All PK studies were designed with the aim of determining doses. The posology adopted was homogeneous across trials testing the same compound, and it was reported on a milligram/kilogram per day basis, which is appropriate in children. On the other hand, heterogeneity in terms of formulations was observed across all of the evaluated trials. It should also be highlighted that none of these studies was designed as a comparative trial testing different PPIs. For omeprazole and esomeprazole, evidence on efficacy and PK emerged from at least three RCTs (in many cases, the trials had a double-blind design).

Of note, in more than $70 \%$ of the efficacy trials, the activity of each drug was evaluated on end points based on the 24-h pH monitoring, often accompanied by an endoscopy.

On the basis of the AEs reported in the trials included in the analysis, all compounds presented a safety profile in children that was comparable with one described in adults. Only in the case of omeprazole were AEs of the respiratory system reported more frequently in children aged $0-2$ years than in adults. This is also confirmed by recent literature data [34]. Two reviews confirmed our findings in terms of the comparability of the omeprazole, lansoprazole, esomeprazole and pantoprazole safety profiles between children and adults [33, 35]. A retrospective observational study that evaluated the long-term safety and efficacy of omeprazole and lansoprazole and involved 166 children reported that PPIs are efficacious and well tolerated for continuous use for as long as 11 years in children [36].

The off-label use of omeprazole, lansoprazole and esomeprazole in children was evaluated as highly appropriate given the consistent available evidence on PK, efficacy and safety (Table 3). Moderate appropriateness was attributed to pantoprazole, due to the lack of PK data and insufficient efficacy trials. Since no adequate evidence 


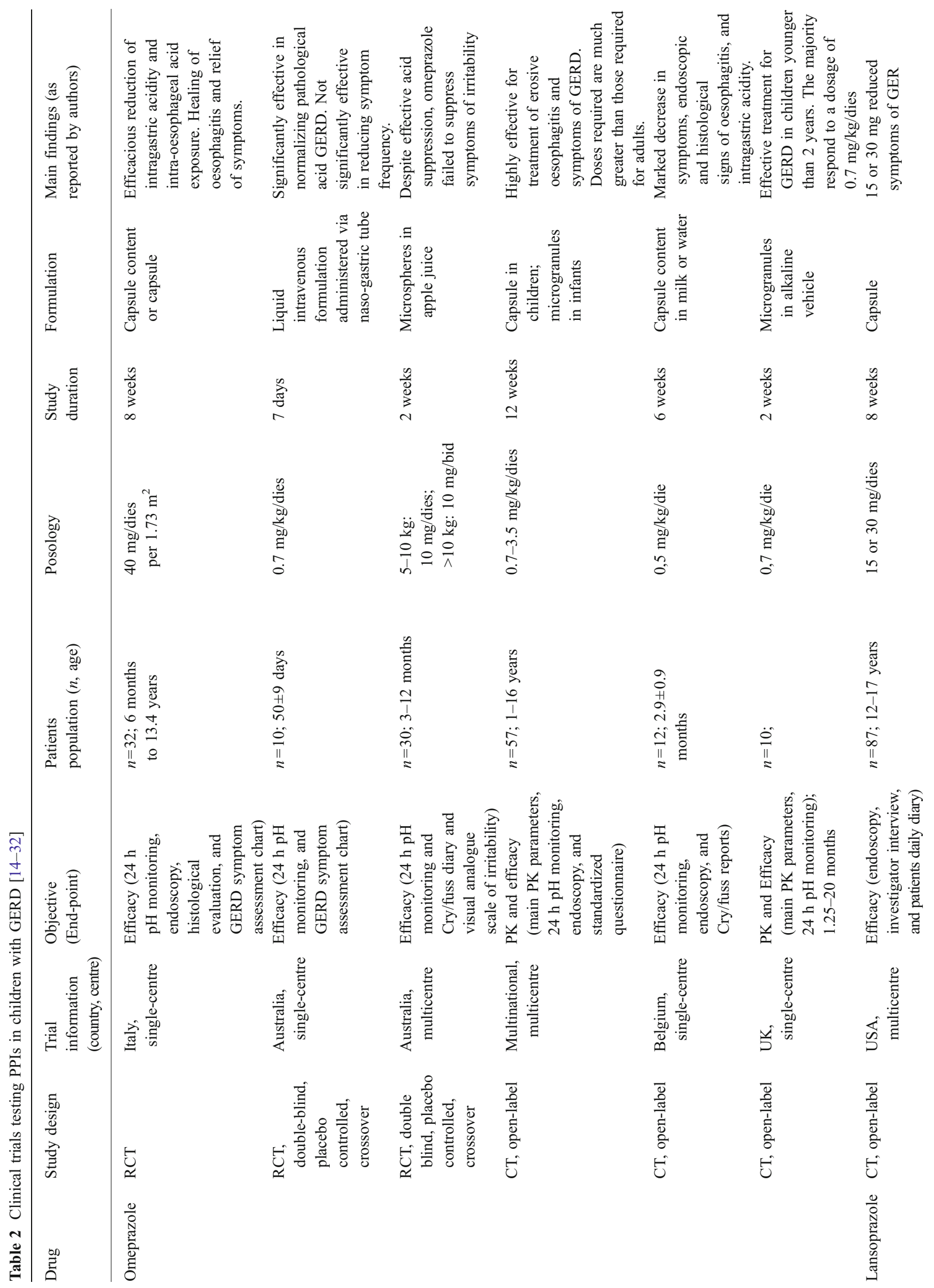




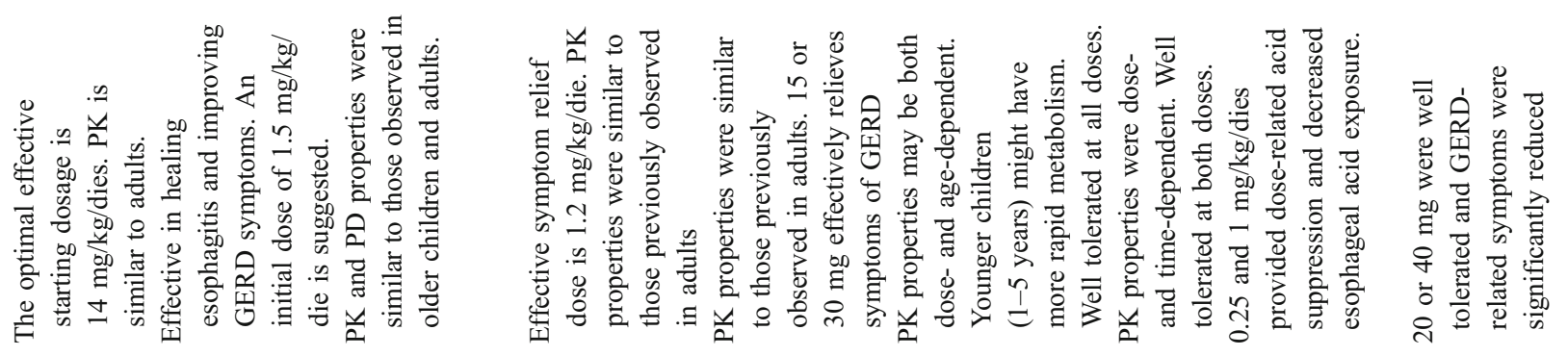

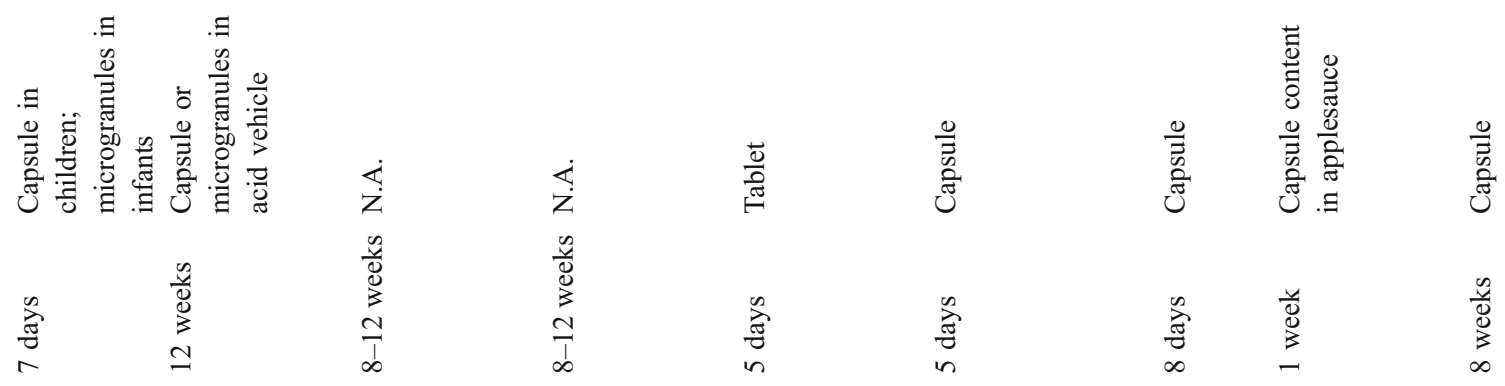

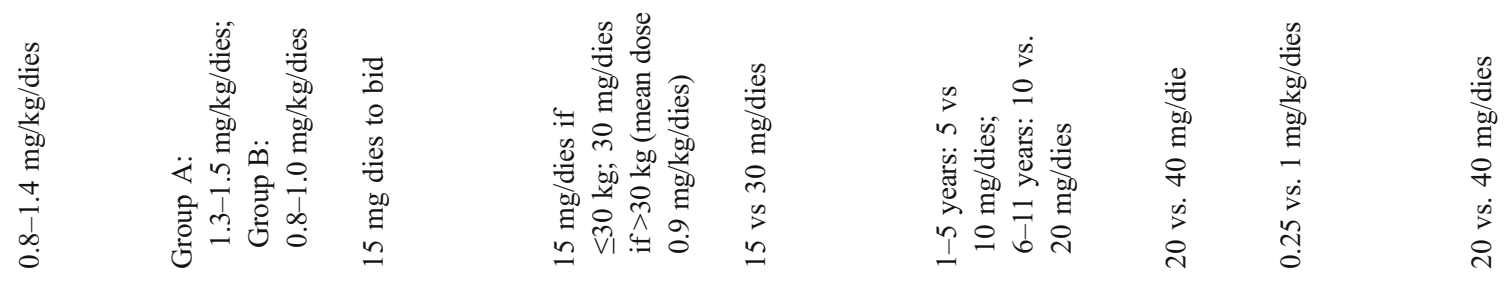

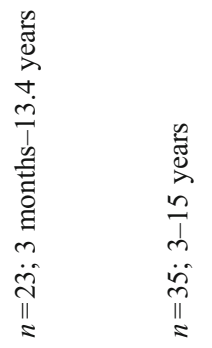

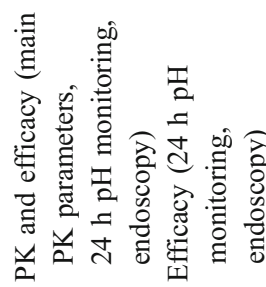

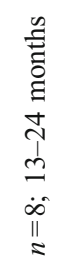

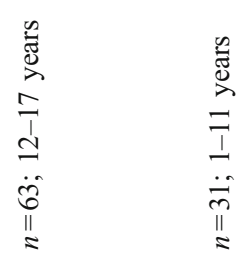

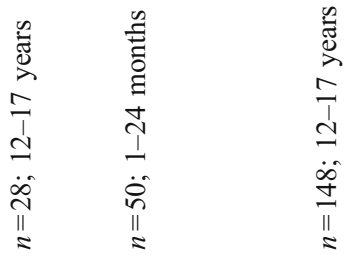

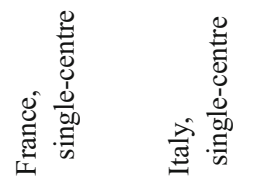

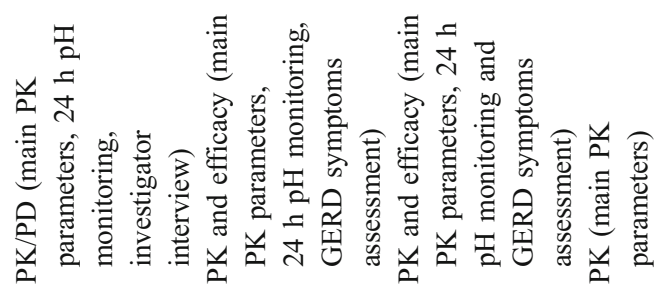

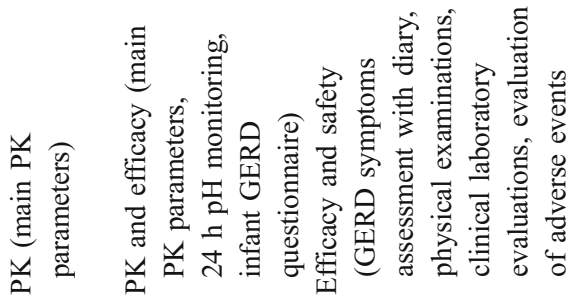

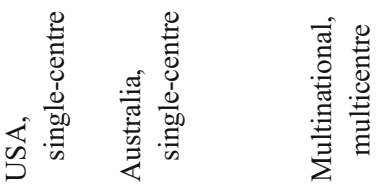

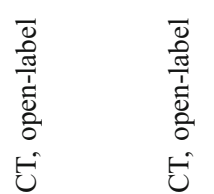

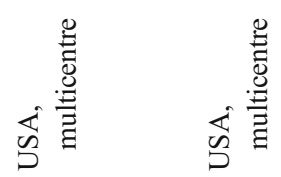

咅

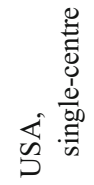

氧总

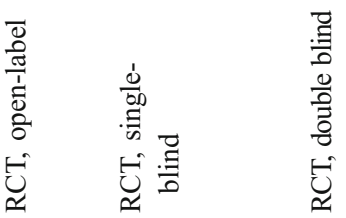

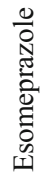




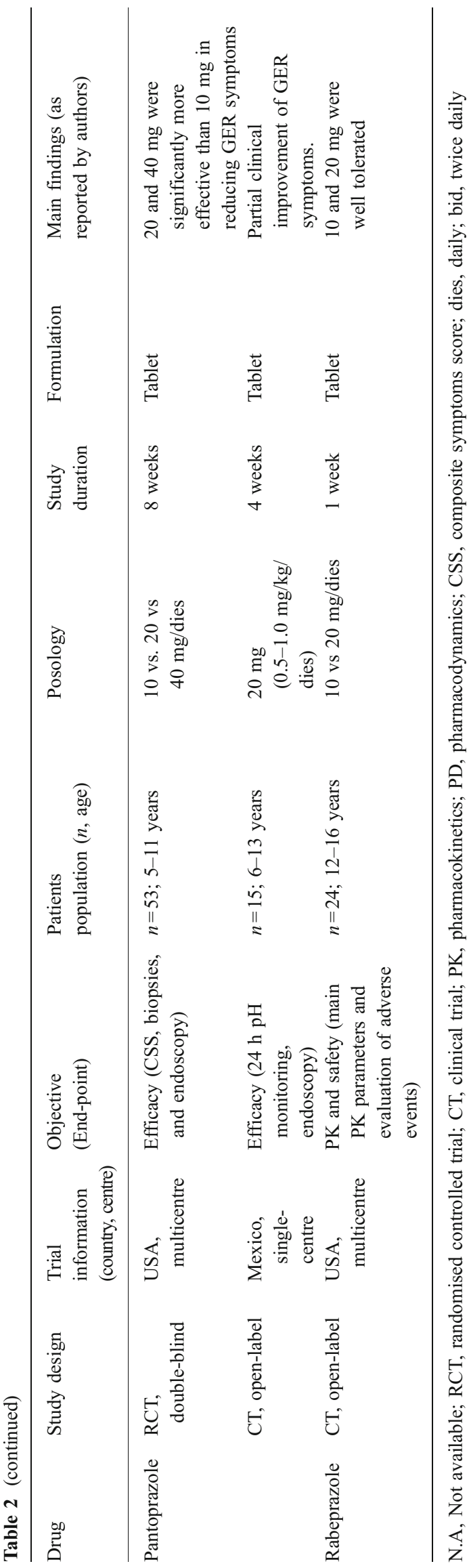

was available for rabeprazole, its off-label use was considered to be scarcely appropriate in children.

\section{Discussion and conclusions}

Of the five authorized PPIs in Europe only one, omeprazole, has a paediatric indication. Consequently, any use of PPIs for the treatment of GERD in patients under the age of 2 years and the paediatric use of all PPIs but omeprazole in patients between 2 and 17 years are to be considered off-label in the EU. Our findings also highlight the discrepancies between regulatory agencies in terms of approved indications (i.e. PPIs for the treatment of GERD in children). Wide discrepancies between the EU and the USA were observed regarding paediatric indications of three compounds, esomeprazole, lansoprazole and pantoprazole. Whereas esomeprazole and lansoprazole are only authorised by the FDA for the treatment of GERD in children aged 1-17 years, pantoprazole was recently reviewed in terms of children posology only in the EU. This heterogeneity could be overcome through the integrated efforts of different regulatory authorities to share more information on the regulatory decision-making process for paediatric drugs. In addition, the incoherence between the posology section and the clinical indication section of the same SPC represents potentially misleading information for prescribers.

According to our analysis, omeprazole, esomeprazole and lansoprazole showed a satisfying level of clinical evidence for paediatric use in the age ranges that are not covered by a formal indication. Those compounds fulfilled all of the criteria for a high appropriateness for administration in children.

A robust clinical data package, i.e. at least two efficacy and two PK trials, and a comparable safety profile between children and adults represent the required level of evidence for avoiding that further paediatric trials are carried out solely for registration and regulatory purposes. This is also in line with the EMEA recommendations on clinical drug development [37-39]. Analysing the available clinical data prior to conducting further trials could be one approach for avoiding the well-known practical and ethical problems related to testing drugs in children. Even when the clinical data package is not robust enough, as in the case of pantoprazole, further testing could be limited only to the missing information.

The case of omeprazole and rabeprazole, respectively evaluated as highly and scarcely appropriate in children, raises further research questions and ethical concerns. In fact, the amount of information available for omeprazole makes the performing of further trials on a molecule of the 
Table 3 Appropriateness of off-label use of PPIs in children with GERD

\begin{tabular}{|c|c|c|c|c|c|}
\hline \multirow{2}{*}{$\begin{array}{l}\text { Criteria used for } \\
\text { classification of } \\
\text { appropriateness }\end{array}$} & \multicolumn{5}{|l|}{ Drugs } \\
\hline & Omeprazole & Lansoprazole & Esomeprazole & Pantoprazole & Rabeprazole \\
\hline $\begin{array}{l}\text { Availability of } \\
\text { clinical trials } \\
\text { for efficacy }\end{array}$ & Yes & Yes & Yes & Yes & No \\
\hline $\begin{array}{l}\text { Availability of } \\
\text { PK data }\end{array}$ & Yes & Yes & Yes & No & No \\
\hline $\begin{array}{l}\text { Comparability } \\
\text { of safety profile } \\
\text { in children versus } \\
\text { adults }\end{array}$ & Yes & Yes & Yes & Yes & No \\
\hline Appropriateness & High & High & High & Moderate & Scarce \\
\hline Comments & $\begin{array}{l}\text { The available evidence } \\
\text { supports the use in } \\
\text { children aged } 0-2 \text { years }\end{array}$ & $\begin{array}{l}\text { The available } \\
\text { evidence supports } \\
\text { the use in children }\end{array}$ & $\begin{array}{l}\text { The available } \\
\text { evidence supports } \\
\text { the use in children }\end{array}$ & $\begin{array}{l}\text { Pharmacokinetic studies } \\
\text { should be conducted to } \\
\text { support use in children }\end{array}$ & $\begin{array}{l}\text { Insufficient } \\
\text { evidence } \\
\text { available } \\
\text { in children }\end{array}$ \\
\hline
\end{tabular}

same class, such as rabeprazole, useless and unethical unless within comparative trials.

It is often reported that the lack of clinical trials in children can be attributable to ethical, methodological and financial issues. However, our analysis shows a different scenario: although there is a consistent amount of published paediatric trials for this specific condition, the use of PPIs for GERD is still considered off-label. Our study also showed the existence of a large amount of clinical evidence on the use of PPIs in children and, therefore, that performing trials in children is feasible.

We believe that the evaluation we carried out on the appropriateness of off-label use of PPIs in children could be easily extended to other classes of drugs or other special populations. Similar analyses could be helpful for prescribers. This would at least allow a more evidence-based approach to off-label prescribing. Moreover, this model could help regulatory authorities identify research priorities for a specific compound (e.g. a further PK study) and require specific mandatory studies for those important questions of efficacy or safety which still remain unresolved. However, most of the retrieved trials were not RCTs and were based on small sample sizes. Regulatory bodies should promote and support the conducting of few large and well-designed trials instead of a multiplicity of small trials with weak methodology. This could contribute to a better protection of the patients from the potential hazards of the off-label use of drugs.

There are two main limitations to our analysis. Firstly, the evaluation of safety in children for each compound was based on information retrieved in published studies (i.e. clinical trials, reviews, observational studies). Given the small number of patients enrolled in clinical trials, only the more frequent events could have been observed and reported in each trial. Secondly, we identified the heterogeneity of formulations used as a potential limitation. However, such heterogeneity is a common problem in studies involving children.

In conclusion, the use of medicines that have not been studied and assessed fully in children is a common situation in Europe as well as the rest of the world.

This study was prepared from a public health perspective. A review of the literature with the aim of searching out published findings can be a useful tool for regulators and policy-makers within the framework of granting children simplified access to medicines. Translating clinical evidence into clinical practice and health-care decision-making could be a useful strategy to fill the gap between regulatory bodies and patients, thereby ensuring an equal and quicker access to medicines.

Acknowledgment After the completion of the article, as from 22 June 2008 Dr. Nello Martini has no longer been a member of the Italian Medicines Agency.

Competing interests The authors belong to regulatory and academic institutions devoted to patients' and national health services' interests. This paper represents the opinion of the authors and does not necessarily reflect the viewpoint of the Italian Medicines Agency and the Medicines Evaluation Board.

Funding The authors did not receive any funds for conducting the present analysis.

Open Access This article is distributed under the terms of the Creative Commons Attribution Noncommercial License which permits any noncommercial use, distribution, and reproduction in any medium, provided the original author(s) and source are credited. 


\section{References}

1. Conroy S, Choonara I, Impicciatore P et al (2000) Survey of unlicensed and off label drug use in paediatric wards in European countries. European Network for Drug Investigation in Children. Br Med J 320:79-82

2. Caldwell PH, Murphy SB, Butow PN et al (2004) Clinical trials in children. Lancet 364:803-811

3. Hoppu K (2008) Paediatric clinical pharmacology - at the beginning of a new era. Eur J Clin Pharmacol 64:201-205

4. Marchetti F, Bua J, Ventura A et al (2007) The awareness among paediatricians of off-label prescribing in children: a survey of Italian hospitals. Eur J Clin Pharmacol 63:81-85

5. US Food and Drug Administration. Pediatric Research Equity Act of 2003. Public Law 108-155 (December 3, 2003)

6. Regulation (EC) No 1901/2006 as amended Regulation (EC) No 1901/2006 of the European Parliament and of the Council of 12 December 2006 on medicinal products for paediatric use and amending Regulation (EEC) No 1768/92, Directive 2001/20/EC, Directive 2001/83/EC and Regulation (EC) No 726/2004. Official Journal of the European Union, Brussels

7. Choonara I (2007) Regulation of drugs for children in Europe. Br Med J 335:1221-1222

8. Assessment of the paediatric needs - gastroenterology. EMEA/ 527934/2007. London, October 2007

9. US Food and Drug Administration (2008) Good reprint practices for the distribution of medical journal articles and medical or scientific reference publications on unapproved new uses of approved drugs and approved or cleared medical devices: draft guidance, Feb 2008. Fed Regist 74(34):9342

10. Psaty BM, Ray W (2008) FDA Guidance on off-label promotion and the state of the literature from sponsors. JAMA 299:1949-1951

11. Rudolph CD, Mazur LJ, Liptak GS et al (2001) Guidelines for evaluation and treatment of gastroesophageal reflux in infants and children: recommendations of the North American Society for Pediatric Gastroenterology and Nutrition. J Pediatr Gastroenterol Nutr 32[Suppl 2]:S1-S31

12. Barron JJ, Hiangkiat T, Spalding J et al (2007) Proton Pump Inhibitor utilization patterns in infants. J Pediatr Gastroenterol Nutr 45:421

13. Khoshoo V, Edell D, Thompson A et al (2007) Are we overprescribing antireflux medications for infants with regurgitation? Pediatrics 120:946-949

14. Cucchiara S, Minella R, Iervolino C et al (1993) Omeprazole and high dose ranitidine in the treatment of refractory reflux oesophagitis. Arch Dis Child 69:655-659

15. Omari TI, Haslam RR, Lundborg P (2007) Effects of omeprazole on acid gastroesophageal reflux and gastric acidity in preterm infants with pathological reflux. J Pediatr Gastroenterol Nutr 44:41-44

16. Moore DJ, Tao BS, Lines DR (2003) Double-blind placebocontrolled trial of omeprazole in irritable infants with gastroesophageal reflux. J Pediatr 143:219-223

17. Hassall E, Israel D, Shepherd R et al (2000) Omeprazole for treatment of chronic erosive esophagitis in children: a multicenter study of efficacy, safety, tolerability and dose requirements. J Pediatr 137:800-807

18. Alliët P, Raes M, Bruneel E (1998) Omeprazole in infants with cimetidine-resistant peptic esophagitis. J Pediatr 132:352-354

19. Bishop J, Furman M, Thomson M (2007) Omeprazole for gastroesophageal reflux disease in the first 2 years of life: a dose-finding study with dual-channel $\mathrm{pH}$ monitoring. J Pediatr Gastroenterol Nutr 45:50-55

20. Fiedorek S, Tolia V, Gold BD (2005) Efficacy and safety of lansoprazole in adolescents with symptomatic erosive and non- erosive gastroesophageal reflux disease. J Pediatr Gastroenterol Nutr 40:319-327

21. Faure C, Michaud L, Shaghaghi EK (2001) Lansoprazole in children: pharmacokinetics and efficacy in reflux oesophagitis. Aliment Pharmacol Ther 15:1397-1402

22. Franco MT, Salvia G, Terrin G (2000) Lansoprazole in the treatment of gastro-oesophageal reflux disease in childhood. Dig Liver Dis 32:660-666

23. Heyman MB, Zhang W, Huang B et al (2007) Pharmacokinetics and pharmacodynamics of lansoprazole in children 13 to 24 months old with gastroesophageal reflux disease. J Pediatr Gastroenterol Nutr 44:35-40

24. Tolia V, Ferry G, Gunasekaran T (2002) Efficacy of lansoprazole in the treatment of gastroesophageal reflux disease in children. J Pediatr Gastroenterol Nutr 35[Suppl 4]:S308-S318

25. Gunasekaran T, Gupta S, Gremse D et al (2002) Lansoprazole in adolescents with gastroesophageal reflux disease: pharmacokinetics, pharmacodynamics, symptom relief efficacy and tolerability. J Pediatr Gastroenterol Nutr 35[Suppl 4]:S327-S335

26. Zhao J, Li J, Hamer-Maansson JE (2006) Pharmacokinetic properties of esomeprazole in children aged 1 to 11 years with symptoms of gastroesophageal reflux disease: a randomized, open-label study. Clin Ther 28:1868-1876

27. Li J, Zhao J, Hamer-Maansson JE (2006) Pharmacokinetic properties of esomeprazole in adolescent patients aged 12 to 17 years with symptoms of gastroesophageal reflux disease: a randomized, open-label study. Clin Ther 28:419-427

28. Omari T, Davidson G, Bondarov P et al (2007) Pharmacokinetics and acid-suppressive effects of esomeprazole in infants 124 months old with symptoms of gastroesophageal reflux disease. J Pediatr Gastroenterol Nutr 45:530-537

29. Gold BD, Gunasekaran T, Tolia V et al (2007) Safety and symptom improvement with esomeprazole in adolescents with gastroesophageal reflux disease. J Pediatr Gastroenterol Nutr 45:520-529

30. Tolia V, Bishop PR, Tsou VM (2006) Multicenter, randomized, double-blind study comparing 10, 20 and $40 \mathrm{mg}$ pantoprazole in children (5-11 years) with symptomatic gastroesophageal reflux disease. J Pediatr Gastroenterol Nutr 42:384-391

31. Madrazo-de la Garza A, Dibildox M, Vargas A et al (2003) Efficay and safety of oral pantoprazole $20 \mathrm{mg}$ given once daily for reflux esophagitis in children. J Pediatr Gastroenterol Nutr $36: 261-265$

32. James L, Walson P, Lomax K et al (2007) Pharmacokinetics and tolerability of rabeprazole sodium in subjects aged 12 to 16 years with gastroesophageal reflux disease: an open-label, single and multiple-dose study. Clin Ther 29:2082-2092

33. Marchetti F, Gerarduzzi T, Ventura A (2003) Proton Pump Inhibitors in children: a review. Dig Liver Dis 35:738-746

34. Berni Canani R, Cirillo P, Roggero P et al (2006) Therapy with gastric acidity inhibitors increases the risk of acute gastroenteritis and community-acquired pneumonia in children. Pediatrics 117:e817-e820

35. Scaillon M, Cadranel S (2002) Safety data required for protonpump inhibitor use in children. J Pediatr Gastroenterol Nutr 35:113-118

36. Hassall E, Kerr W, El-Serag HB (2007) Characteristics of children receiving proton pump inhibitors continuously for up to 11 years duration. J Pediatr 150:262-267

37. Note for guidance on statistical principles for clinical trials. EMEA/CPMP/ICH/363/96. London, September 1998

38. Points to consider on application with 1. meta-analyses; 2 . one pivotal study. EMEA/CPMP/EWP/2330/99. London, 31 May 2001

39. Guideline on the role of pharmacokinetics in the development of medicinal products in the paediatric population. EMEA/CHMP/ EWP/147013/2004/Corr. London, 28 June 2006 